\title{
Legally Acceptable Representative
}

National Cancer Institute

\section{Source}

National Cancer Institute. Legally Acceptable Representative. NCI Thesaurus. Code C142600.

An individual or juridical or other body authorized under applicable law to consent, on behalf of a prospective subject, to the subject's participation in the clinical trial. (ICH) 